\title{
Playing When Paying and What Happens Next: Customer Satisfaction and Word-of-Mouth Intention in Gambled Price Promotions
}

\author{
Karl Akbari (D) Udo Wagner iD
}

Accepted: 18 March 2021 / Published online: 28 April 2021

(C) The Author(s) 2021

\begin{abstract}
Gambled price promotions, i.e., discounts in which the customers' savings depend on the outcome of a game, have recently gained increasing attention from research and practice. This type of promotion is often framed as an in-store event, and consumers experience two properties inherent in gambling: entertainment and varied financial payoffs. Depending on the consumers' assessments of these two elements, these experiences might drive two postpurchase consequences of such campaigns: customer satisfaction with the retailer and word-of-mouth intention. To assess these effects, two field quasi-experiments with gambled price promotions were conducted: one in a candy store and the other in a retail furniture store. Two main findings emerge from these studies: (1) The customers in both studies endorse gambled price promotions and are more willing to engage in word-of-mouth when participating in such a campaign. The effect of gambled price promotions on customer satisfaction is positive in the low-stakes setting of the candy store but insignificant in the furniture store. (2) The positive effects of such promotions are mediated by their entertainment value and moderated by the consumers' assessments of the discount. The implication of these results is that, in addition to the already known revenue-increasing prepurchase effects, gambled price promotions can also
\end{abstract}

This paper was originally submitted and independently peer-reviewed at Schmalenbach Business Review, one of SBUR's predecessor journals. It has been accepted by the same Editor-in-Chief for publication in the successor journal SBUR.

K. Akbari $(\triangle)$

School of Management, National Taiwan University of Science and Technology, No. 43, Keelung Rd., Sec. 4, Da'an District, Taipei City 106335, Taiwan

E-Mail: karl.akbari@mail.ntust.edu.tw

K. Akbari · U. Wagner

Department of Marketing and International Business, University of Vienna,

Oskar-Morgenstern-Platz 1, 1090 Vienna, Austria

E-Mail: udo.wagner@univie.ac.at 
result in positive postpurchase effects and should represent a valuable addition to the seller's promotion toolbox.

Keywords Gambled price promotion - Probabilistic discount · Price promotion · Entertainment $\cdot$ Retail $\cdot$ Experiential value $\cdot$ Promotional games · Word-of-mouth · Customer satisfaction

\section{JEL Classification M31}

\section{Introduction}

The Sugar Shop is a regional icon in the German city of Heidelberg that sells a wide variety of sugary confections. When one of the authors was still a child and had little pocket money, his schoolmates shared rumors about the legendary shop, which is stuffed with sweets from top to bottom. More than licorice sticks, wine gums, and chocolate, his friends reported that the quirky owner determined an item's price by throwing dice with customers. The author did not receive this tip exclusively: When Prince William and his wife Kate visited Heidelberg in 2017, a digital magazine (Kendi-Prill 2017) asked local citizens which sights the royals should not miss; the Sugar Shop (Heidelberger Zuckerladen) was ranked in second place after the famous Heidelberg Castle.

What differentiates the Sugar Shop from other stores is that when items are placed on sale, customers are not offered a fixed discount percentage (e.g., 10\% discount). Instead, they are offered an unknown and gambled discount (e.g., items are freeof-charge for customers who roll triple sixes). For these promotions, the savings amount is, as the name suggests, vaguely defined at the time of purchase and can differ between customers.

Recent studies have shown that in-store price promotions with unknown discounts can have numerous advantages over promotions with fixed outcomes. For example, companies can achieve the same profits with lower costs (Dhar et al. 1995). Furthermore, customers tend to favor unknown discounts over regular discounts when the expected value of either discount type is statistically identical (Goldsmith and Amir 2010; Ailawadi et al. 2014; Mazar et al. 2017).

While the previous research has shown that consumers prefer to buy from sellers when promotions with unknown discounts are present, much less is known about the effect of gambled promotions on customers' postpurchase evaluations after participating and learning the actual outcome of the promotion. However, like other components in the marketing mix, promotions and prices can also influence consumer attitudes, intentions, and behaviors, which, in turn, can affect the firm's profitability in the long run.

Two processes might impact consumers' postpurchase evaluations in promotions with unknown consequences: On the one hand, customers who enjoy the diversion of the promotion or who enjoy gambling per se might find such a promotion appealing or entertaining. Unusual promotions, such as the one from the Sugar Shop, might be better retained in long-term memory, and shoppers might come to associate the 
seller with positive feelings. This outcome can, in turn, engender higher customer satisfaction and increased word-of-mouth (WOM). On the other hand, gambled promotions inevitably produce winners (e.g., the customer with triple sixes in the above example) and losers (e.g., the customer who rolls any other number). Thus, a small proportion of customers can profit from gambled promotions whereas the majority of customers would have profited from the fixed outcome promotion. Consequently, consumers who feel that they have won might enjoy participation in promotion more while those who believe that they have lost might experience feelings of unhappiness or regret. Therefore, the positive experiential effects of the promotion and, therefore, customer satisfaction and WOM might be mitigated by the outcome of the gamble.

This paper contributes to the literature by examining how customers perceive price promotions with unknown discounts after their participation and whether they transfer their corresponding experiences to the evaluation of the store and their WOM intention.

The structure of the remainder of this paper is as follows. Section 2 reviews the existing research on promotions with unknown discounts and presents the hypothesis development. Section 3 describes two field studies, section 4 discusses the findings of these field studies, and section 5 concludes.

\section{Literature Review}

\subsection{Price Promotions with Unknown Discounts}

Although promotions with fixed outcomes are by far the most widely used discount format, companies are increasingly offering promotions with discounts that are unknown at the time of purchase (Ailawadi et al. 2014). These promotions involve risk or uncertainty and thus offer the customer not only the chance to win a relatively substantial discount but also the risk of receiving a relatively low discount or even no discount.

Most standard economic theories assume a risk-averse decision-maker, in which case a definite outcome is preferred over a probabilistic outcome when provided with two options with identical statistical expectations. However, some circumstances encourage risk-seeking behaviors. The possibility effect of prospect theory holds that decision-makers overestimate small probabilities and behave optimistically. Decision-makers prefer large gains with low probabilities over low-to-moderate gains with medium-to-high probabilities (Kahneman and Tversky 1979; Bar-Hillel and Budescu 1995; Bar-Hillel et al. 2008). Moreover, uncertainty can work positively and motivate consumers when they focus more on the process of reward pursuit than on the outcome of the promotion (Shen et al. 2015). These (mis)judgments can work in favor of a promotion with unknown discounts and make such promotions more attractive than they would appear under purely rational considerations.

To date, several studies have confirmed the effectiveness of promotions involving unknown discounts with respect to stimulating sales. Many of these studies focus on the ability of promotions with unknown outcomes to influence the consumer before making a purchase decision. Then, the uncertainty is resolved, and the consumer 
gets to know the discount. In an early study, Dhar et al. (1995) showed that fuzzily stated discounts compared to promotions with fixed rebates can lead to increased purchase intentions and sales.

Since then, a number of studies have highlighted the factors associated with the prepurchase dominance of promotions with unknown consequences over traditional promotions. Promotions with unknown consequences appear particularly advantageous for less important and less thoughtful purchasing decisions. In particular, they are more effective than secure discounts with the same expected value when the probabilities of winning are low (Dhar et al. 1995; Lee et al. 2019), the discounts in the sure promotion seem small (Gaertig and Simmons 2020), the decision is affective (Laran and Tsiros 2013), and when the customer does not focus on the gist of a choice but on its details (Duke et al. 2018). Furthermore, when customers are very optimistic about their chances of winning, initial optimism positively affects the evaluation of uncertainty-based discounts such that the gamble is evaluated on par with its best possible outcome (Goldsmith and Amir 2010). The preference for gambled promotions is explained by the consumer's wish to save money (Fang and Mowen 2009) paired with optimism (Dahr et al. 1995; Goldsmith and Amir 2010), risk-seeking behavior (Vries and Zhang 2020), and a reduction in the pain of payment (Lee et al. 2019). Similarly, Ailawadi et al. (2014) modeled consumer responses to discounts in which a price reduction is given conditionally on an event occurring after the purchase. The authors identified three groups that vary in their responsiveness to conditional rebates. The characteristics that distinguish these groups from one another are the level of perceived savings, entertainment benefits, event involvement, thinking costs, and proneness to gambling. Compared to fixed price promotions, conditional rebates appear to incur fewer costs to the seller but yield additional communicational effects.

Researchers attempted to evaluate the impact of the framing of such promotions and sought to explain the optimal design of discounts with unknown consequences. Kamleitner et al. (2011) find that consumers prefer risky promotions on a peritem basis compared to a per-purchase basis. Mazar et al. (2017) demonstrate that probabilistic promotions induce higher purchase rates and higher quantities when they include the possibility of getting the entire purchase for free compared to probabilistic promotions with the same expected value but no possibility to "win it all".

In addition to promotions that grant a discount at the time of purchase, some authors investigate consumer responses to promotions in which the consumer plays the game before making the actual purchase. Thus, consumers know whether they are among the winners or losers of the promotion before making the purchase decision. For winners, Hock et al. (2020) document an increase in conversion rates and spending. Consumers who feel lucky about their win attach a positive feeling to the promotion and the seller and redeem the coupon more often than customers who receive a fixed discount coupon of the same value. However, consumers might question the legitimacy of a coupon from such a prepurchase gamble and reject the coupon when they have high choice freedom needs (Briley 2018).

To date, most of the research on price promotions with unknown consequences has tried to explain how they influence sales and how they compete with traditional 
promotions in the prepurchase decision-making of the buyer. However, very little attention has been paid to the impact of such promotions on the consumer after the discount has been realized. A notable exception is given by Alavi et al. (2015) who focus on changes in the internal reference price after participation in a gambled promotion. In retailing, discounting is a common practice, and over time, customers reduce their internal reference price, which makes it difficult for the retailer to charge regular prices. For price promotions with unknown consequences, this adaptation process is less pronounced.

In addition to the internal reference price, promotions with unknown consequences could influence other postpurchase valuations of the buyer. By participating in the promotion, consumers might receive a (potentially very large or very small) discount or enjoy the entertainment aspect of the promotion. This could change consumers' evaluations of the purchase experience and their satisfaction with the seller and spark WOM. To date, this aspect of uncertain promotions has received scant attention in the research literature. This study seeks to fill this void.

\subsection{Hypotheses Development}

Our framework considers three potential consequences of price promotions with uncertain outcomes: entertainment value $(\mathrm{H} 1)$, customer satisfaction $(\mathrm{H} 2 \mathrm{a}, \mathrm{H} 2 \mathrm{~b}$, $\mathrm{H} 3 \mathrm{a}, \mathrm{H} 3 \mathrm{~b}$ ), and WOM intention (H4a, H4b, H4c). Our overall research model is presented in Fig. 1.

To date, the literature has discussed promotions in which consumers remain passive while the seller or an external event determines the profit (e.g., Ailawadi et al. 2014; Mazar et al. 2017; Shen et al. 2019) and others in which consumers actively participate in the promotion and take matters into their own hands by participating in a promotional game (e.g., Alavi et al. 2015; Hock et al. 2020). In this research, we concentrate on the latter (i.e., gambled price promotions, Alavi et al. 2015) as the entertainment value of such promotions should be higher than in promotions without consumer participation.

\subsubsection{Gambled Price Promotions and Entertainment Value}

In contrast to traditional price promotions, in gambled promotions, consumers are engaged in price setting. The seller offers customers an experience that actively involves them and allows them to be immersed in a gamble. Such framing might provide a particular appeal for participants (Pine and Gilmore 1998).

Gambling is commonly associated with entertainment, distraction, and leisure (Walker 1992); thus, the primary motivation for gambling is often to have fun rather than to win money (Francis et al. 2015). Therefore, participating in a gamble could create entertainment value on the consumer side (Fang and Mowen 2009).

Chandon et al. (2000) define entertainment value as the extent to which the consumer perceives a sales promotion as being intrinsically fun to see or use. Entertain- 


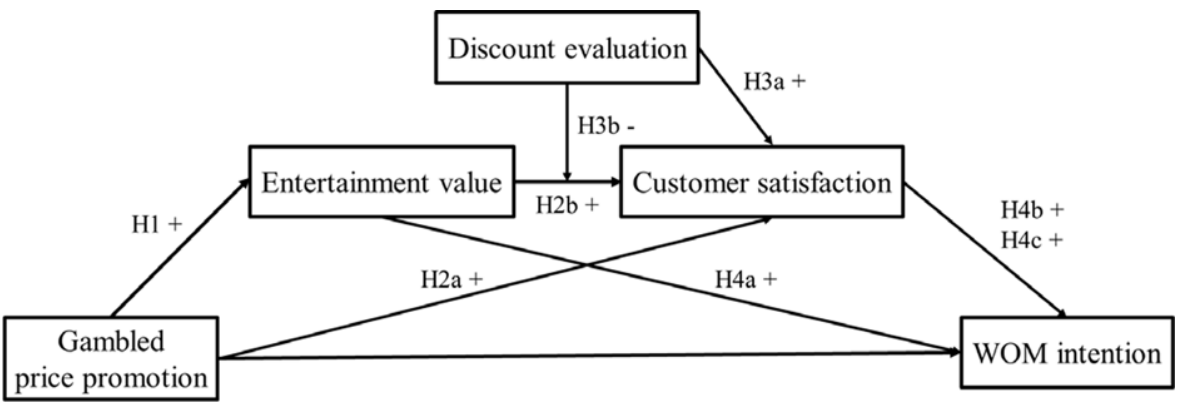

Fig. 1 Conceptual model

ment value is seen as a hedonic benefit resulting from active or passive participation in a sales promotion. ${ }^{1}$

The enjoyableness of a promotion with unknown outcomes is an important success factor (Ward and Hill 1991). The previous studies have shown that consumers who participate in online sweepstakes value the entertainment component of such contests (Gedenk et al. 2001). Furthermore, customers indicate that the task of a contest might be more important than the prizes themselves (Teichmann et al. 2005). Therefore, we expect gambled price promotions to yield higher entertainment value than regular, fixed price promotions:

H1 Gambled price promotions result in higher entertainment value compared to regular promotions or nonpromotional settings.

\subsubsection{Gambled Price Promotions and Customer Satisfaction}

In recent decades, customer satisfaction has been established as a central metric in the field of marketing for researchers and practitioners alike. Ultimately, customer satisfaction leads to stronger customer loyalty and higher profitability (Barsky and Nash 2003). For companies aiming to manage customer satisfaction, gambled promotions might offer favorable outcomes. The confirmation/disconfirmation paradigm states that consumers form beliefs and expectations about the seller's quality. When the seller meets or exceeds the consumer's expectations, the consumer will be satisfied, and conversely, consumers will be dissatisfied when the seller underperforms

\footnotetext{
1 Note the different definitions of entertainment value in the literature. Pine and Gilmore (1998) characterize consumer experiences along two dimensions, customer participation (active/passive) and connection (absorption/immersion). They classify experiences that are passive and absorbing (e.g., watching TV) as entertainment. Experiences that require active participation and immersion, such as gambling, are classified as escapist. Consequently, gambled promotions should also be primarily escapist according to this definition. The other two prototypes of experience are esthetic (passive/immersion) and educational (active/ absorption). However, they note that experience qualities are multidimensional and not mutually exclusive and that rich experiences encompass all four endpoints of the spectrum. Interestingly, they refer to gambling in a casino as such a rich experience.
} 
(Oliver 1980; Churchill and Surprenant 1982; Krüger 2016; Santini et al. 2018; Chung et al. 2020).

Prices constitute a vital dimension of the seller's performance, and the extant research identifies them as a determinant of customer satisfaction (Oliver 1999; Zeithaml and Bitner 2000; Martín-Consuegra et al. 2007). To a buyer, a gambled price promotion offers the possibility of making the purchase at a lower price than in nonpromotional settings. Thus, when a gambled promotion is present, the seller can provide a better consumption experience and exceed the customer's expectations more easily than in the absence of a promotion. Gambling-prone customers will enjoy participating in promotions that involve risk and, in turn, are likely to form more positive associations with the store than risk-averse customers. Moreover, customers might capitalize on other promotion-specific benefits, e.g., novelty (Mazar et al. 2017). As novelty increases the evaluation of different stimuli (Berlyne 1970), gambled promotions could mean variety and stimulation for the customer, which increases the preference for such promotions (Sheth et al. 1991). Hence, the expectations for the seller's service offering can be exceeded when an innovative promotion is present compared to when it is not and, therefore, customer satisfaction should be higher. Furthermore, a positive endorsement of the promotion might also cause spillover effects in the sense that the store's attributes are judged more positively when the campaign is present than when absent (Forgas 1999).

H2a Gambled price promotions increase customer satisfaction compared to regular promotions or nonpromotional settings.

As discussed above, gambling is commonly associated with entertainment. For the seller, the entertainment derived from a gambled promotion is an option to introduce experiential value to the shopping experience. Consumers increasingly focus on a shopping experience rather than on products (Pine and Gilmore 1998). Through their participation in gambled promotions, consumers undergo experiences in the store and are stimulated. This can improve the perception of the value of the purchase decision, brand, or company with which the consumer interacts (Schmitt 1999). In addition to the discount that is also provided in the case of fixed discounts, a seller that uses gambled pricing offers an additional, emotional value component (Gee et al. 2005). The previous research shows that creating experiential value during a service encounter can increase customer satisfaction (Yuan and Wu 2008). With a specific focus on entertainment, the extant research has found that the more positive the evaluation of the entertainment component of a service encounter, the greater the customer satisfaction (Söderlund and Julander 2009; Pantano and Naccarato 2010). Therefore, entertainment value is a mediator in the gambled price promotioncustomer satisfaction relationship. Thus, we propose the following:

H2b Entertainment value mediates the relationship between a gambled price promotion and customer satisfaction with the store; specifically, gambled price promotions increase entertainment value, such that the higher the entertainment value is, the higher the customer satisfaction is. 
Consumers might evaluate the realized discount as part of the overall performance of the seller. The different outcomes of a gambled price promotion can leave some consumers better off than what they expected before participating and others worse off than expected. In line with the traditional wisdom regarding satisfaction, consumers make assessments of the outcome of the gamble and should be more satisfied with their purchase and the retailer when their expectations are confirmed or exceeded and less satisfied when their expectations are disconfirmed (Holbrook et al. 1984). However, if the expectations and assessments of the promotion are rational, the effect should even out across all consumers compared to a traditional promotion of the same expected value: some consumers might receive a higher discount and will, therefore, be more satisfied; others might receive a lower discount and will, correspondingly, be less satisfied.

However, when consumers have little knowledge or ability to evaluate the outcome of an experience, they have difficulty assessing and elaborating that outcome correctly (Alba und Hutchinson 1987). More specifically, consumers have difficulties assessing and judging the outcome of a gamble, and the evaluation of the results of the game may be subjective (Gilovich 1983; Gilovich and Douglas 1986). Therefore, it is not clear who feels like a winner and who feels like a loser. Even players with sound statistical knowledge are vulnerable to cognitive biases in gambling situations (Benhsain and Ladouceur 2004).

In the present study, discount evaluation is defined as the subjective assessment of the realized discount a customer receives. Consumers who indicate that they are satisfied with the discount have high discount evaluations; consumers who indicate that they are dissatisfied have low discount evaluations.

When consumers believe that their discount is favorable and allows them to save money, their expectations of the seller's overall performance should be met or exceeded. Again, this comparison should spark customer satisfaction. Therefore, we propose the following:

H3a The higher the discount evaluation is, the higher the customer satisfaction is.

As argued above in support of $\mathrm{H} 2$, higher entertainment values increase customer satisfaction. This relationship is expected to be moderated by the discount evaluation.

The impact of entertainment value on customer satisfaction is reduced when consumers have more positive discount evaluations. Buyers whose evaluations of the discount are positive will consider themselves to be (lucky) winners and experience the "joy of winning". Therefore, overall, they might be in a better mood (Smith et al. 2009). This might produce a halo effect such that even customers who see little entertainment value in the promotion might, therefore, still be more satisfied with the seller when they think they have "won" in the gamble.

Reciprocally, when customers obtain high entertainment value from the promotion, they might be satisfied with the seller regardless of whether they evaluate the gamble as being a "win" or a "loss". While consumers who are disappointed by the outcome of the gamble will consider themselves to be (unlucky) losers and experience the "frustration of losing" (Ding et al. 2005; Astor et al. 2013), the influence of 
entertainment value on customer satisfaction produce a halo effect that overshadows the negative evaluation of the outcome. Therefore, we hypothesize the following:

H3b The discount evaluation moderates the relationship between entertainment value and customer satisfaction with the store such that under lower discount evaluations, the impact of entertainment value on customer satisfaction will be more favorable than under higher discount evaluations.

\subsubsection{Gambled Price Promotions and WOM Intention}

WOM is defined as informal communication among consumers about their experiences and opinions regarding a seller's goods or services (Westbrook 1987). Companies often try to engage consumers in WOM as it constitutes free marketing to potential new customers.

We argue that the entertaining nature of gambled promotions provides an opportunity for increased WOM. Participating in a gamble is likely to evoke arousal and emotions (Gee et al. 2005; Malhotra 2010). Consumers are known to share emotions with others (Heath et al. 2001; Peters and Kashima 2007). If consumers perceive a price promotion as a stimulating and positively entertaining experience, they will be expected to share that experience. As an example, Lovett et al. (2013) show that the excitement of a brand is associated with more WOM. A second argument that supports higher WOM intention in the case of higher entertainment value is that consumers are more likely to discuss topics that they find exciting and interesting because they do not want to be associated with boringness (Levy 1959; Berger 2014). In line with this reasoning, consumers are more likely to discuss unusual rather than ordinary products (Berger and Schwartz 2011; Berger and Iyengar 2013). This should also hold for interesting rather than boring promotions. The previous research shows that more differentiated sellers receive more WOM (Lovett et al. 2013). From a practitioner's point of view, Sernovitz (2006, p. 6) writes, “... nobody talks about boring companies, boring products or boring ads". Consistent with this reasoning, a higher entertainment value offers more opportunity for the buyer to talk about something interesting.

H4a A higher entertainment value increases WOM intention.

The relationship between consumer satisfaction and WOM is well documented. Various researchers have detected a positive relationship between customer satisfaction and WOM (Holmes and Lett 1977; Swan and Oliver 1989; Schlesinger and Heskett 1991; Roberts 2004). Among other reasons, consumers share their satisfaction because they want to help their peers find a suitable product, want to appear knowledgeable, share useful information, and reduce cognitive dissonance (Dichter 1966; Arndt 1967; Berger 2014). This is also expected in our research. ${ }^{2}$ Together with $\mathrm{H} 1$ and $\mathrm{H} 2 \mathrm{~b}$, the relationship between gambled price promotions and WOM

\footnotetext{
2 Note that there is also evidence for increased (negative) WOM even for low levels of satisfaction (Richins 1983; Anderson 1998). However, in this paper, we account for only positive WOM intention.
} 
intention should be sequentially mediated by entertainment value and customer satisfaction:

H4b Entertainment value through customer satisfaction mediates the positive relationship between gambled price promotions and WOM intention.

Similarly, together with $\mathrm{H} 3 \mathrm{a}$, when a discount evaluation has an influence on customer satisfaction, it should also transfer to WOM intention:

H4c Customer satisfaction mediates the positive relationship between discount evaluation and WOM intention.

\section{Empirical Investigations}

The empirical part of this paper reports on two quasi-experimental field studies. Study I describes a quasi-experiment that compares entertainment value, customer satisfaction, and WOM intention of gambled promotions with regular discounts and no discount conditions. Study II does not include a regular discount condition and compares gambled promotions only to the no discount case.

Study I was conducted in a candy shop whose buyers spent, on average, €10 per visit. The expected pay-off amounted to $5 \%$ in risky and certain discount scenarios. Study II analyzed a gambled price promotion offered by a large retail furniture chain. The management of the company designed the campaign and allowed us to interview their customers. This access made it possible to investigate a high-stakes situation: the promotion offered an expected discount of $10.5 \%$ on each customer's invoice.

\subsection{Study I: Price Promotion with a "Wheel of Fortune"}

\subsubsection{Method}

A small candy shop operating in a downtown neighborhood of the capital of a central European country served as the setting for Study I. The owner managed the store and did not hold promotions regularly; thus, gambled price promotions were entirely novel to this shop. The quasi-experiment employed a one-factor (four levels) between-subjects design with promotional campaigns as the manipulated variable; CG1: no discount; CG2: regular promotion of 5\% discount for all consumers; EG1: gambled price promotion (expected discount: 5\%, range: 1-10\%); EG2: (gambled) probabilistic free price promotion (expected discount: 5\%, range: 1-100\%).

We considered two different distributions of the discount level to test the robustness of our hypotheses $\mathrm{H} 3 \mathrm{a}$ and $\mathrm{H} 3 \mathrm{~b}$. While the average discount of a risky price promotion is likely evaluated on economic considerations by the seller, its distribution might matter to the consumer. In line with the above considerations, promotions with more dispersed discount distributions (i.e., such that a few consumers win large amounts but leave the majority with low discounts) should lead to more customers 


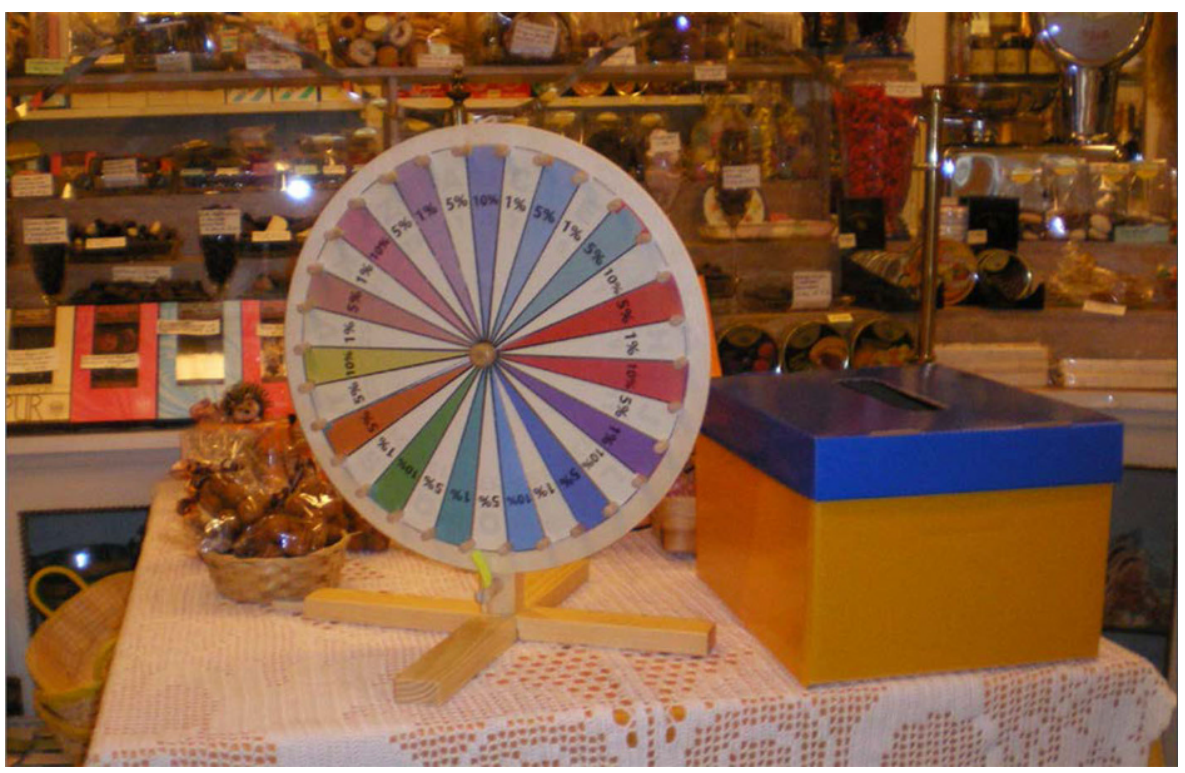

Fig. 2 Setting for Study I (EG1)

being dissatisfied with the outcome of the promotion than in cases with narrower distributions (where more consumers receive intermediate discounts). EG1 represents a narrower distribution with discounts between $1 \%$ and $10 \%$ but many cases of 5\%. EG2 represents a more dispersed distribution and gives possible discounts of $100 \%$ to some consumers. These promotions have previously been referred to as "probabilistic free price promotions" (Mazar et al. 2017). However, as the expected discount stays the same, most consumers receive only a very low discount of $1 \%$.

Data were collected on the shop's premises at four separate time points. The nonpromotional slot began on week 1 (CG1), and the gambled price promotion began on week 2 (EG1). Then, a two-week period with no treatment followed to minimize spillover effects. During week 5, the candy shop offered the gambled probabilistic free price promotion (EG2). Last, a few weeks later, regular price promotion with a fixed discount of $5 \%$ followed (CG2). To ensure that consumers did not participate in more than one condition, we used an individual identification code (a combination of initials and birthday). No extraneous incidents occurred during the study period that might have distorted the results of this study.

The gambled promotion was framed as a "wheel of fortune". Similar to a roulette, the wheel carried 30 pockets, and each of these pockets corresponded to a percentage discount (cf. Fig. 2). The assignment of levels of discount to these pockets resulted in an average concession of 5\% under both experimental conditions. However, EG2 assigned a $100 \%$ discount to a single pocket, which was flagged by unique coloring to increase the visibility of that pocket. Accordingly, the other pockets offered relatively lower markdowns.

Research assistants surveyed all customers during the field study. For CG1, the questionnaire contained only questions on the general evaluation of the store (cus- 
tomer satisfaction, WOM intention) and demographics. For the other conditions, the discount campaign was carried out at the cashier's counter. After the customers made their purchase decision, the research assistants explained the promotion in detail (EG1, EG2, and CG2) and invited shoppers to participate in the game (EG1, EG2). Before playing, the respondents indicated their anticipated pay-off. After spinning the wheel and familiarizing themselves with their discount, all the respondents completed a questionnaire soliciting their opinions on the discount obtained, the entertainment value of the promotion, their satisfaction level, their WOM intention, and demographic variables (age, gender).

The busy atmosphere at the check-out area motivated the use of single-item scales to measure all of these variables in a time-efficient manner (cf. Appendix Table 5). The responses were recorded by itemized five-point rating scales, where 1 represented the most unfavorable evaluation and 5 represented the most favorable evaluation. The research assistants also collected data concerning the value of the purchase and the actual discount achieved. We surveyed all customers during the observation period. The study included 51 customers in EG1 (29\% male), 68 customers in EG2 (24\% male), 74 customers in CG1 (32\% male), and 34 customers in CG2 (35\% male). The slightly smaller sample size for CG2 was due to a shortened data-collection period. All customers participated in the promotion (EG1, EG2, and CG2).

\subsubsection{Results}

Descriptive Statistics The upper panel of Table 1 provides the descriptive statistics for Study I. As expected, a substantial discrepancy was found between expected (EG1: 36\%, EG2: 21\%) and realized discounts (EG1: 6\%, EG2: 3\%), the former being significantly higher. Consumers overestimated their expected discount in both experimental conditions. The overall realized discount approximated what had been expected (i.e., 5\%). Nevertheless, the subjects still held favorable impressions of the realized discount (EG1: 4.33, EG2: 3.41, CG2: 4.47) for all experimental conditions that offered a promotion (when compared to the mean of the scale [i.e., 3]). Previously held expectations seemed to have been discarded in this evaluation as we did observe a relationship between the objective outcome of the gamble and subjective evaluation of the discount: the higher the obtained discount is, the higher the satisfaction with the discount is $(r=0.23, p<0.01)$. Furthermore, there is a promotional effect: Average purchase values for EG1 (13.57€), EG2 (17.68€), and CG2 (12.78€) outperform their corresponding benchmark in CG1 (9.23€) (no discount).

A preliminary investigation of customer satisfaction and WOM intention in the upper panel of Table 1 shows consistently higher averages for EG1 and EG2 than for CG1 and CG2. The entertainment values in EG1 and EG2 are higher than those in CG2. The discount evaluation is similarly high in EG1 and CG2 but lower in EG2. MANOVA tests confirmed that these differences were statistically significant (cf. Appendix Table 6). Furthermore, customer satisfaction and WOM intention were positively and significantly correlated with entertainment value (cf. Table 2). The correlations between discount evaluations and customer satisfaction and WOM 
Table 1 Descriptive statistics (Study I, II)

\begin{tabular}{|c|c|c|c|c|c|c|c|c|c|}
\hline \multirow[t]{2}{*}{ Study I } & \multirow[t]{2}{*}{$n$} & $M$ & $\mathrm{SD}$ & $\mathrm{M}$ & SD & $\mathrm{M}$ & SD & $\mathrm{M}$ & SD \\
\hline & & \multicolumn{2}{|c|}{$\begin{array}{l}\text { Expected discount } \\
(\%)\end{array}$} & \multicolumn{2}{|c|}{$\begin{array}{l}\text { Realized discount } \\
(\%)\end{array}$} & \multicolumn{2}{|c|}{$\begin{array}{l}\text { Entertainment } \\
\text { value }^{a}\end{array}$} & \multicolumn{2}{|c|}{$\begin{array}{l}\text { Purchase value } \\
\text { (€) }\end{array}$} \\
\hline EG1 & 51 & 36 & 41 & 6 & 4 & 4.31 & 0.85 & 13.57 & 12.22 \\
\hline EG2 & 68 & 21 & 37 & 3 & 12 & 4.16 & 1.20 & 17.68 & 15.34 \\
\hline CG1 & 74 & - & - & - & - & - & - & 9.23 & 8.82 \\
\hline \multirow[t]{2}{*}{ CG2 } & 34 & 5 & - & 5 & - & 3.53 & 1.19 & 12.78 & 12.76 \\
\hline & & \multicolumn{2}{|c|}{$\begin{array}{l}\text { Discount evalua- } \\
\text { tion }^{a}\end{array}$} & \multicolumn{2}{|c|}{$\begin{array}{l}\text { Customer satis- } \\
\text { faction }^{a}\end{array}$} & \multicolumn{2}{|c|}{ WOM intention $^{a}$} & - & - \\
\hline EG1 & & 4.33 & 1.08 & 4.96 & 0.20 & 4.91 & 0.45 & - & - \\
\hline EG2 & & 3.41 & 1.43 & 4.75 & 0.61 & 4.78 & 0.60 & - & - \\
\hline CG1 & & - & - & 4.59 & 1.11 & 4.58 & 1.09 & - & - \\
\hline CG2 & & 4.47 & 0.75 & 4.50 & 0.66 & 4.53 & 0.79 & - & - \\
\hline Study II & $n$ & \multicolumn{2}{|c|}{$\begin{array}{l}\text { Expected discount } \\
(\%)\end{array}$} & \multicolumn{2}{|c|}{$\begin{array}{l}\text { Realized discount } \\
(\%)\end{array}$} & \multicolumn{2}{|c|}{$\begin{array}{l}\text { Entertainment } \\
\text { value }^{a}\end{array}$} & \multicolumn{2}{|c|}{$\begin{array}{l}\text { Purchase value } \\
(€)\end{array}$} \\
\hline$\overline{\mathrm{EG}}$ & 99 & 9 & 6 & 11 & 3 & 4.11 & 0.82 & 201.52 & 338.72 \\
\hline \multirow[t]{2}{*}{$\mathrm{CG}$} & 167 & - & - & - & - & - & - & 181.33 & 272.23 \\
\hline & & \multicolumn{2}{|c|}{$\begin{array}{l}\text { Discount evalua- } \\
\text { tion }^{a}\end{array}$} & \multicolumn{2}{|c|}{$\begin{array}{l}\text { Customer satis- } \\
\text { faction }^{a}\end{array}$} & \multicolumn{2}{|c|}{$W$ M intention ${ }^{b}$} & - & - \\
\hline EG & - & 3.91 & 1.24 & 3.94 & 1.20 & 2.87 & 0.34 & - & - \\
\hline CG & - & - & - & 3.90 & 0.34 & 2.57 & 0.62 & - & - \\
\hline $\mathrm{KW}^{\mathrm{c}}$ & - & - & - & $\mathrm{KW}=3.66$ & $p=0.06$ & $\mathrm{KW}=17.91$ & $p<0.01$ & - & - \\
\hline
\end{tabular}

EG1: gambled discount (average: 5\%, range: 1-10\%), EG2: gambled discount (average: 5\%, range: 1-100\%), CG1: no discount, CG2: regular discount $5 \%$

EG: gambled discount (average: $10.5 \%$, range: $3-18 \%$, CG: no discount)

a-point scale

b 3-point scale

${ }^{\mathrm{c}}$ Kruskal-Wallis test

Table 2 Preliminary investigation of the correlation between entertainment value and discount evaluation and customer satisfaction and WOM intention (Study I, II)

\begin{tabular}{llllll}
\hline Correlations & \multicolumn{2}{l}{ Customer satisfaction } & \multicolumn{2}{l}{ WOM intention } \\
\hline $\begin{array}{l}\text { Study I } \\
(\text { EG1, EG2) }\end{array}$ & $\begin{array}{l}\text { Entertainment } \\
\text { value }\end{array}$ & $0.42^{\mathrm{c}}$ & $p<0.01$ & $0.27^{\mathrm{c}}$ & $p<0.01$ \\
$\begin{array}{l}\text { Study II } \\
(\text { EG) }\end{array}$ & $0.05^{\mathrm{c}}$ & $p=0.63$ & $0.32^{\mathrm{d}}$ & $p<0.01$ \\
$\begin{array}{l}\text { Study I } \\
(\text { EG1, EG2) }\end{array}$ & $\begin{array}{l}\text { Discount } \\
\text { evaluation }\end{array}$ & $0.09^{\mathrm{c}}$ & $p=0.25$ & $0.08^{\mathrm{c}}$ & $p=0.33$ \\
$\begin{array}{l}\text { Study II } \\
(\text { EG) }\end{array}$ & & $0.24^{\mathrm{c}}$ & $p=0.02$ & $0.10^{\mathrm{d}}$ & $p=0.34$ \\
\hline
\end{tabular}

${ }^{a}$ EG1: gambled discount (average: 5\%, range: 1-10\%), EG2: gambled discount (average: 5\%, range: $1-100 \%)$

${ }^{\mathrm{b}}$ EG: gambled discount (average: $10.5 \%$, range: $3-18 \%$ )

${ }^{c}$ Pearson correlation coefficient

d Spearman's rank correlation coefficient 
intention were positive but not significant (cf. Table 2). Overall, this provides initial support for an effect of gambled price promotions on the endogenous variables.

Testing the mediation hypotheses necessitates a focus on promotions that offer a discount (EG1, EG2, and CG2). Our model can be decomposed into a moderated mediation model (gambled price promotion $\rightarrow$ entertainment value $\rightarrow$ customer satisfaction, moderator: discount evaluation) and a sequential mediation model (gambled price promotion $\rightarrow$ entertainment value $\rightarrow$ customer satisfaction $\rightarrow$ WOM intention, also including the mediation discount evaluation $\rightarrow$ customer satisfaction $\rightarrow$ WOM intention).

Investigating Entertainment Value, Discount Evaluation, and Customer Satisfaction (H1-H3b) We hypothesized that entertainment value mediates the effect of gambled price promotions (with $\mathrm{CG} 2$ as a reference category) on customer satisfaction. Furthermore, we hypothesized a direct effect of discount evaluation on customer satisfaction and a moderating effect of discount evaluation on the path between entertainment value and customer satisfaction. The summary statistics of these analyses are by and large satisfactory (cf. Table 3, row 7).

The results provided evidence for a significant effect of gambled price promotions on entertainment value for both conditions (Table 3, rows 1 and 2). The direct effects of gambled price promotional conditions (EG1, EG2) on entertainment value differed significantly from those of the fixed discount condition (CG2) but not from each other.

The direct effects of entertainment value and discount evaluation on customer satisfaction were significant (Table 3, rows 3 and 4). Additionally, controlling for the presence of gambled price promotions, we found a significant (negative) moderating effect of discount evaluation on the relationship between entertainment value and customer satisfaction (Table 3, row 5). When discount evaluation is low to medium, entertainment value increases customer satisfaction more than when discount evaluation is high (cf. Fig. 3a).

The significance of the indirect effects of the proposed moderated mediation was assessed using a bootstrapping approach of a PROCESS model (Hayes 2018). Gambled price promotions have a significant positive indirect effect on customer satisfaction (Table 3, rows 15a and 16a). However, we do not find moderated mediation (Table 3 , rows $15 \mathrm{~b}$ and $16 \mathrm{~b}){ }^{3}$

Since the moderator (discount evaluation) was continuous, we looked for the turning points for where exactly, in the absolute value of the moderator, the effect of entertainment value turns from significance to nonsignificance (for a prespecified significance level of 0.05). This is done using the Johnson-Neyman technique (Bauer and Curran 2005; Krishna 2016). The turning point from significance to nonsignificance of the effect of entertainment value is 4.36 (cf. Fig. 3b). Entertainment value is associated with significantly greater customer satisfaction for values of discount evaluation below 4.36 (measured on a 5-point scale). When discount evaluation is

\footnotetext{
3 The absence of a significant moderated mediation effect justifies that we report indirect effects for mean discount evaluation only.
} 


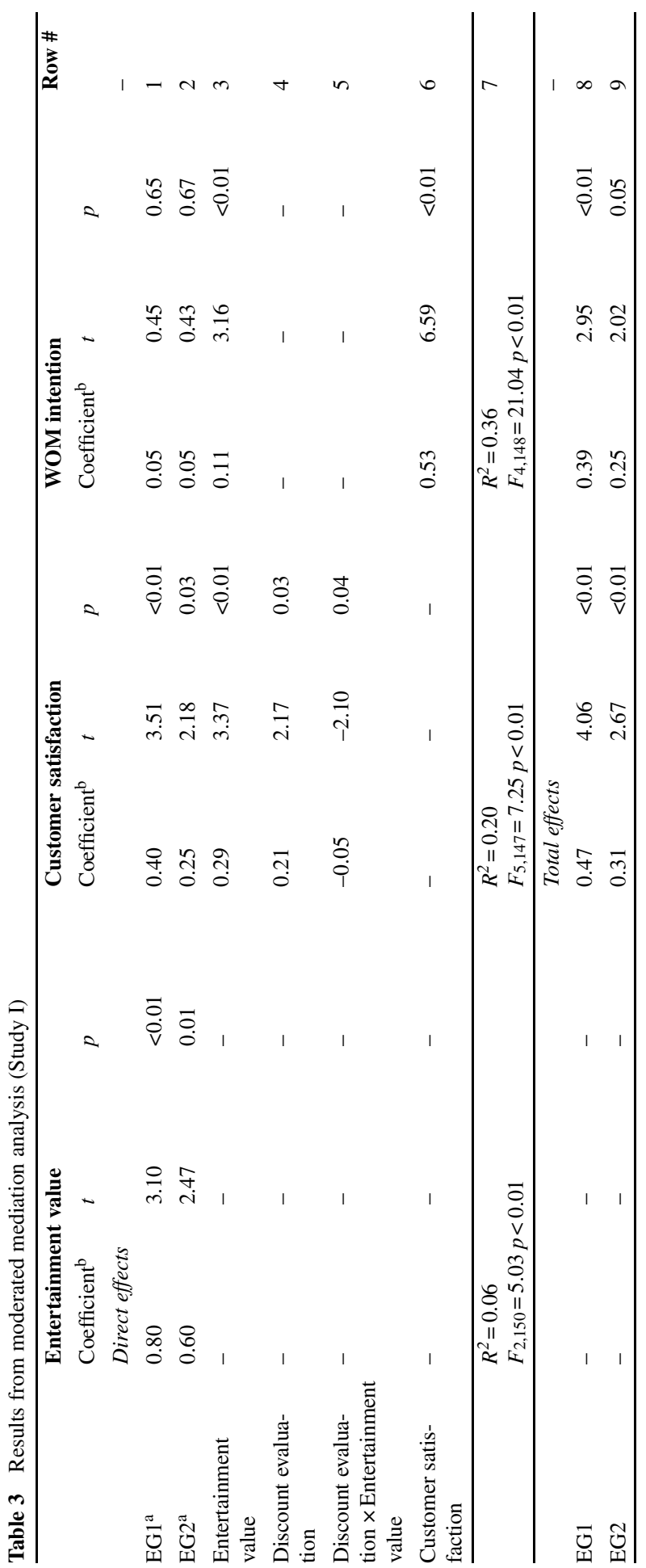




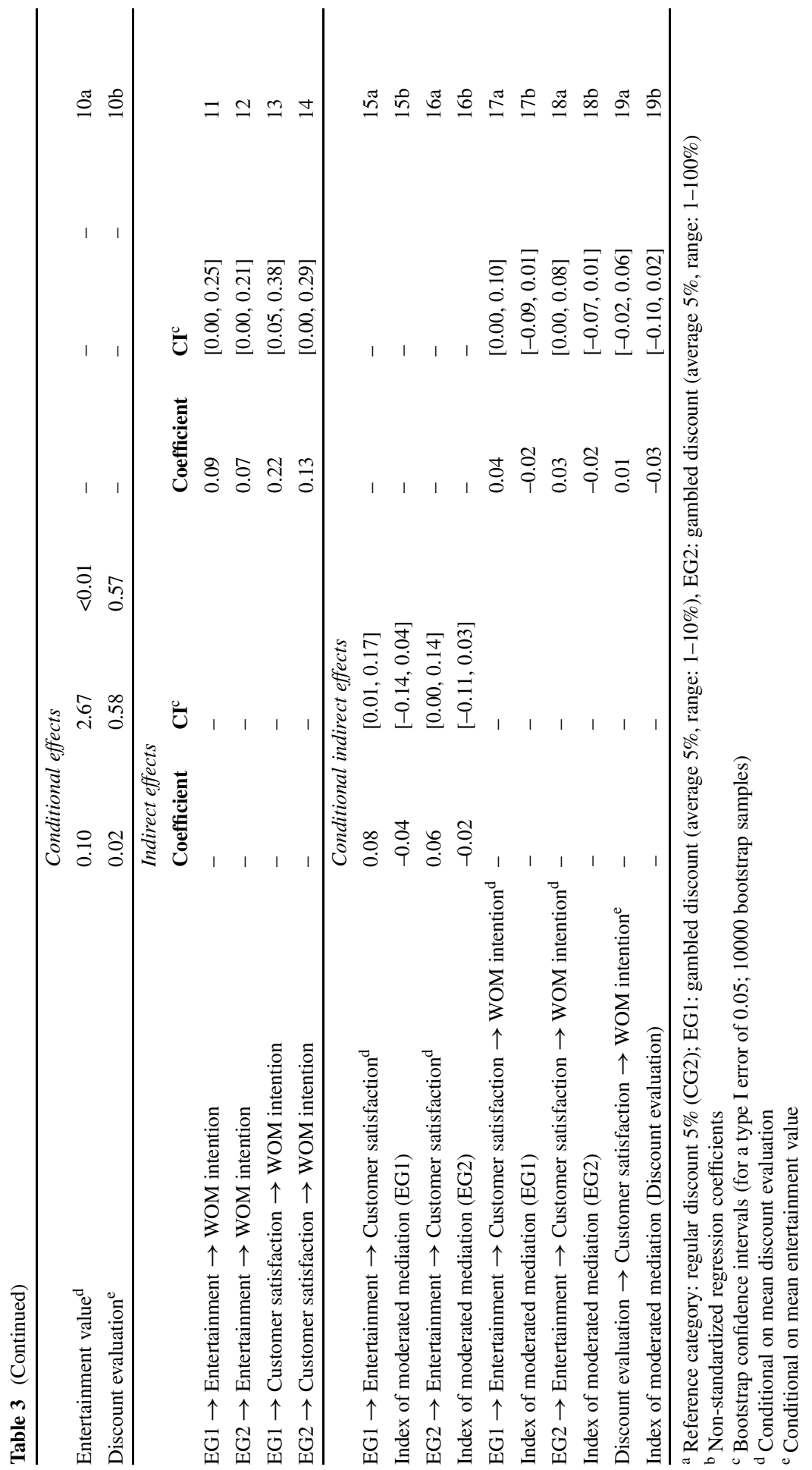


a

Interaction plot

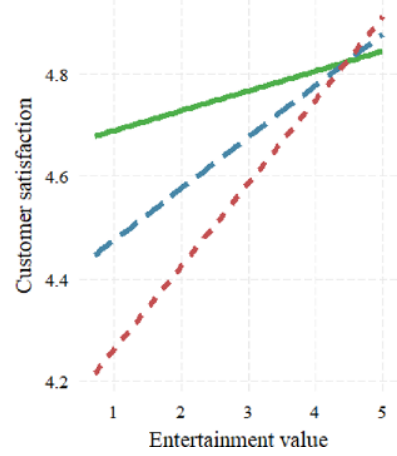

b

Johnson-Neyman plot

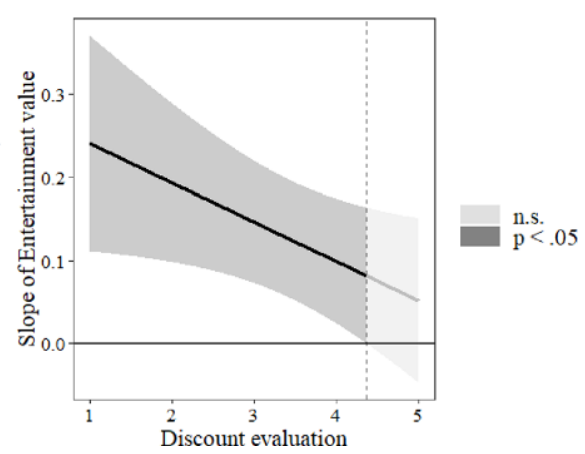

Fig. 3 Results of moderation analysis

greater than 4.36, the differences between customer satisfaction at high and low levels of entertainment values are not significant.

The direct and the total effects of gambled price promotions on customer satisfaction were significant, indicating partial moderated mediation (Table 3, rows 1, 2, 8 and 9).

Investigating WOM Intention (H4a-H4c) We estimated the serial mediation from gambled price promotion (with CG2 as a reference category) through entertainment value and customer satisfaction with WOM intention. The direct effects of entertainment value and customer satisfaction were positive and significant (Table 3, rows 3 and 6).

Using PROCESS, we established that gambled price promotion had an indirect effect on WOM intention through entertainment value and customer satisfaction (Table 3, rows 11 to 14). Discount evaluation did not have a significant indirect effect on WOM intention (Table 3, row 19a). Furthermore, we could establish a significant serial mediation for both gambled price conditions (Table 3, rows 17a and 18a). However, we did not find moderated (serial) mediation (Table 3, rows $17 \mathrm{~b}$ and $18 \mathrm{~b}$ ). ${ }^{3}$

Finally, the total effects of gambled price promotion on WOM intention were significant (Table 3, rows 8 and 9) but there was no direct effect (Table 3, rows 1 and 2), indicating full serial mediation with respect to the type of promotion.

As a side-note, we add that sociodemographic variables (i.e., gender, age) were not found to be influential on consumers' assessments of entertainment value, discount evaluation, customer satisfaction, and WOM intention.

\subsubsection{Discussion}

For customer satisfaction, we find support for our hypotheses. Gambled price promotions increase the entertainment value (H1). The significant indirect effects of gambled promotions on customer satisfaction indicate that entertainment value mediates this relationship $(\mathrm{H} 2 \mathrm{a})$. Both direct effects of entertainment value and dis- 
count evaluations were positive and significant $(\mathrm{H} 2 \mathrm{~b}$ and $\mathrm{H} 3 \mathrm{a})$. Furthermore, the relationship between entertainment value and customer satisfaction is moderated by discount evaluation $(\mathrm{H} 3 \mathrm{~b})$. When discount evaluations are high, entertainment value is not a driver of customer satisfaction. High discount evaluations suffice to achieve satisfaction. However, when discount evaluations are low, entertainment drives satisfaction. In other words, the seller can compensate for the low discount evaluations with higher entertainment values. This offers the seller the possibility to maintain high customer satisfaction despite the consumers' unhappiness with the deal.

With respect to WOM intention both entertainment value and customer satisfaction (H4a and H4b) significantly positively influence WOM intention. The effect of discount evaluation on WOM intention is not significant $(\mathrm{H} 4 \mathrm{c})$. Furthermore, there is no direct effect of gambled promotions on WOM intention.

Considering two different distributions of gambled discounts allowed us to observe a potential constraint for the positive effect of gambled promotions on customer satisfaction and WOM intention. When more consumers obtain lower discounts and therefore evaluate the outcome of the gamble less favorably, the positive effects of gambled promotions become weaker.

\subsection{Study II: Price Promotion Using Dice}

On the one hand, Study II offers a conceptual replication of Study I (Lynch et al. 2015); both studies offer a comparable setting regarding the type of promotion. By playing a game of chance, the customer takes an active role in determining the discount they receive. The result of the game is random, and the customer can only influence the outcome by playing. On the other hand, the studies differ in several respects. First, Study II considers only two experimental conditions. Second, with mean article prices exceeding $€ 100$, risk-involving promotions in furniture stores are high-stakes gambles (Wagner and Jamsawang 2012). The high-stakes situation is a distinguishing feature of Study II because most research on risky and uncertain discounts has dealt with hypothetical scenarios or very low pay-off situations (e.g., possible gains averaged $<€ 5$ ). Third, the average discount level of $10.5 \%$ is higher than the discount level in Study I (5\%). Higher stakes and higher discount levels might emphasize the economic aspects of the promotion over its entertainment value. Fourth, the assessment of the expected discount might be easier this time ${ }^{4}$, which might increase the salience of perceived wins and losses. Fifth, in contrast to the candy shop in Study I, this furniture retailer regularly offers several kinds of traditional and gambled price promotions. Thus, customers of this retailer might have become more accustomed to gambled promotions, which reduces its novelty. Therefore, this study aims to find limiting conditions for our results in Study I.

\footnotetext{
4 Assessing the expected value is easier for calculating the average number of points achieved when rolling dice three times versus for a wheel of fortune with 30 pockets.
} 


\subsubsection{Method}

The study took place in a large furniture store chain operating in the same central European country. The quasi-experiment employed a one-factor (two levels) between-subjects design with exposure/no exposure to a gambled price promotion as the manipulated variable. Data were collected in an outlet located in a metropolitan area at two separate time points. Customers of the store who made purchases during the promotional week comprised the experimental group (EG); those who made purchases 5 weeks later during the nonpromotional week comprised the control group (CG). Both data collection periods were comparable with respect to other relevant internal or external influences.

The store's administrative personnel invited customers to participate in a game using dice after having paid at the check-out. The shoppers rolled three dice and received a discount according to the number of points they obtained (e.g., if the three dice showed three, four, and five points, respectively, shoppers received $3+$ $4+5=12 \%$ off the purchase invoice). In addition to the discount, this campaign was designed to be enjoyable. A moderator contributed to the inherently event-like character of the promotion (e.g., throwing oversized dice in public) (cf. Fig. 4).

Trained research assistants intercepted all customers who participated in the promotion (EG). Before the dice were rolled, shoppers indicated their expected discount level. After throwing the dice, the shoppers again answered queries on their discount evaluation, the entertainment value of the promotion, customer satisfaction, WOM intention, and demographics (age, gender). The research assistants observed the purchase value and the outcome of the dice game (i.e., the actual discount achieved).

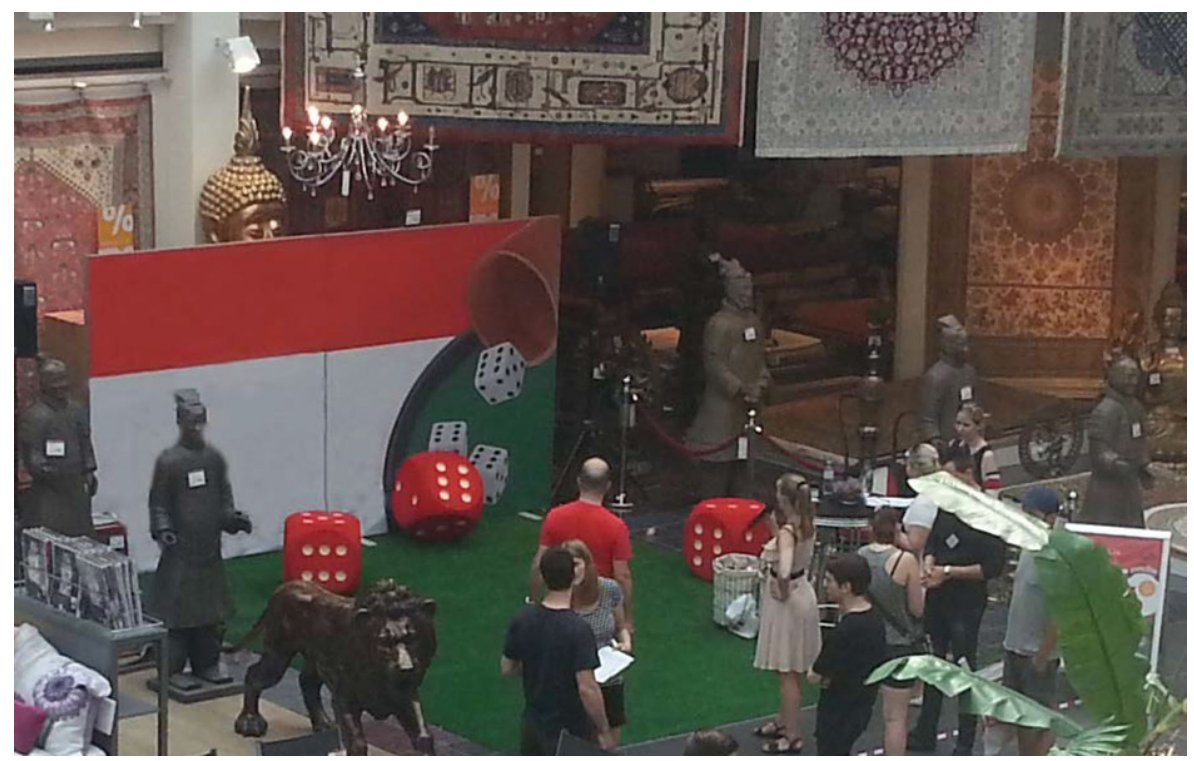

Fig. 4 Setting for Study II (EG) 
No promotional events were held in this outlet five weeks later, at which point the customers were surveyed again (CG). This time, the questionnaire contained only questions on customer satisfaction, WOM intention, and demographics. The EG comprised 99 participants (31\% male), and the CG comprised 167 participants (51\% male). The sampling plans were a census in EG and systematic cluster sampling in CG. The smaller sample size for EG was because not all customers chose to participate in the dice game. This might be due to the customer's time constraints, as participation in the promotion could have included some waiting.

To keep the burden for the participants as small as possible, and to comply with the request of the manager of the retail chain, we employed single item measures as in Study I (cf. Table 5). Furthermore, to be consistent with the usual measurement of the retailer and in contrast to Study I, WOM intention was measured on a threepoint scale.

\subsubsection{Results}

Study II did not aim to test the full research model. Analyses are restricted to comparing outcomes for gambled promotion (EG) and no promotion (CG). Furthermore, the analyses of the effects of the gambled promotion on customer satisfaction and WOM intention were restricted to the EG case, i.e., conditional on entertainment value.

Descriptive Statistics The lower panel of Table 1 provides descriptive statistics for Study II. A cursory inspection of the expected discount seems to imply that the respondents' expectations of the discount (9\%) came close to reality (i.e., 10.5\%). However, this was the case for only approximately one-third of the participants. The large standard deviation is evidence that many shoppers expressed irrational expectations (either very low [i.e., $\leq 3 \%$ ] or very high [i.e., $\geq 18 \%]$ ). Given the sample size, the average realized discount corresponds to the probabilistic evidence $(11 \%)$. Nonetheless, the respondents were pleased with the realized discount (mean value of 3.91 when compared to the mean of the scale [i.e., 3]). The purchase values were slightly higher in the experimental condition than in the control condition. However, the standard deviations are large throughout because of the wide assortment of items available in this store and the corresponding diversity of basket values.

In the EG, the average evaluation of the entertainment value (4.11) surpassed (significantly) the midpoint of the scale (i.e., 3). A comparison across studies reveals that entertainment values are of the same size. However, customer satisfaction (3.94) is not. Additionally, oral reports from the research assistants who interviewed customers affirmed a pleasant atmosphere throughout the event. Thus, some evidence points in the direction of a substantial entertainment value provided by this promotion. Average customer satisfaction was nearly identical in both groups (EG: 3.94, CG: 3.90); however, the substantial standard deviation for EG and the weakly significant Kruskal-Wallis test indicate that the distribution of satisfaction between the two groups was different. Customer satisfaction was more dispersed (i.e., U-shaped) for the EG but bell-shaped for the CG. A significant Kruskal-Wallis test indicates 
that WOM intention was higher in the EG (2.87 on a three-point scale) than in the CG (2.57).

A preliminary investigation (cf. Table 2) identifies positive and significant correlations between customer satisfaction with discount evaluation and WOM intention with entertainment value.

Investigating Customer Satisfaction and WOM Intention We analyzed the proposed moderated mediation. When testing the relevant parts of our model, we hypothesized that customer satisfaction mediates the effect of entertainment value on WOM intention. Furthermore, we hypothesized a significant moderating effect of discount evaluation on the relationship between entertainment value and customer satisfaction. This model allows us to test the effect of entertainment value on customer satisfaction and WOM intention. Hence, customer satisfaction is both a focal variable for $\mathrm{H} 2 \mathrm{~b}$ and $\mathrm{H} 3 \mathrm{a}, \mathrm{H} 3 \mathrm{~b}$ and a predictor/mediator for $\mathrm{H} 4 \mathrm{~b}$ and $\mathrm{H} 4 \mathrm{c}$. As our dependent variable for $\mathrm{H} 4 \mathrm{a}-\mathrm{H} 4 \mathrm{c}$, WOM intention is measured only on a three-point scale, using ordinary least squares is not advisable. Therefore, we transformed the data to a binary variable (intention to recommend versus no intention to recommend) and ran a binary logistic regression.

The results did not show evidence for a significant relationship between entertainment value and customer satisfaction (Table 4, row 1). However, the relationship between discount evaluation and customer satisfaction was significant (Table 4, row 2). The moderating effect of discount evaluation on the relationship between entertainment value and customer satisfaction was insignificant (Table 4, row 3). Furthermore, the relationship between customer satisfaction and WOM intention was insignificant (Table 4, row 4). This also holds for the indirect effects of entertainment and discount evaluation via customer satisfaction (Table 4 , rows $7 \mathrm{a}, 8 \mathrm{a}$ ). In addition, moderated meditation of entertainment value and discount evaluation is not significant (Table 4 , rows $7 \mathrm{~b}$ and $8 \mathrm{~b}$ ). ${ }^{3}$ However, we find a direct effect of entertainment value on WOM intention (Table 4, row 1) and a total effect of entertainment value on WOM intention (Table 4, row 6).

\subsubsection{Discussion}

We did not find support for our hypothesis with respect to customer satisfaction. The effect of entertainment value on customer satisfaction was insignificant, as was the moderating effect of discount evaluation. However, discount evaluation had a positive direct effect on customer satisfaction. This points to a potential boundary condition of entertainment value as a driver for customer satisfaction in gambled promotions. For higher expected discount levels, customer satisfaction is less driven by entertainment value and more driven by monetary considerations.

With respect to WOM intention, we can partially support our hypotheses. While we did not find an indirect effect of entertainment value and discount evaluation on WOM intention via customer satisfaction ( $\mathrm{H} 4 \mathrm{~b}, \mathrm{H} 4 \mathrm{c})$, we found a direct effect of entertainment value on WOM intention (H4a). This suggests that consumers are more likely to recommend the store when they find the promotion entertaining. However, discount evaluation did not have a direct or indirect effect. 
Table 4 Results from moderated mediation analysis (Study II)

\begin{tabular}{|c|c|c|c|c|c|c|c|}
\hline & \multicolumn{3}{|c|}{ Customer satisfaction } & \multicolumn{3}{|c|}{ WOM intention } & \multirow{2}{*}{$\begin{array}{l}\text { Row } \\
\#\end{array}$} \\
\hline & Coefficient $\mathrm{t}^{\mathrm{a}}$ & $t$ & $p$ & Coefficient $^{\mathrm{a}}$ & Wald & $p$ & \\
\hline & \multicolumn{6}{|l|}{ Direct effects } & \\
\hline Entertainment value & 0.04 & 0.26 & 0.79 & 1.12 & 7.94 & $<0.01$ & 1 \\
\hline Discount evaluation & 0.23 & 2.37 & 0.02 & -0.11 & -0.15 & 0.70 & 2 \\
\hline $\begin{array}{l}\text { Discount evalua- } \\
\text { tion } \times \text { Entertainment } \\
\text { value }^{\mathrm{b}}\end{array}$ & 0.22 & 1.79 & 0.08 & - & - & - & 3 \\
\hline \multirow[t]{3}{*}{ Customer satisfaction } & - & - & - & 0.36 & 2.03 & 0.15 & 4 \\
\hline & \multicolumn{3}{|c|}{$\begin{array}{l}R^{2}=0.10 \\
F_{3,95}=3.55 p=0.02\end{array}$} & \multicolumn{3}{|c|}{$\begin{array}{l}\text { McFadden } R^{2}=0.14 \\
\text { Omnibus } \chi_{3}^{2}=10.72 p=0.01\end{array}$} & 5 \\
\hline & - & - & - & Total effect & & & - \\
\hline \multirow[t]{3}{*}{ Entertainment value } & - & - & - & 1.06 & 7.56 & $<0.01$ & 6 \\
\hline & - & - & - & \multicolumn{3}{|c|}{ Conditional indirect effects } & - \\
\hline & - & - & - & Coefficient & $\mathrm{CI}^{\mathrm{c}}$ & & - \\
\hline $\begin{array}{l}\text { Entertainment } \rightarrow \text { Cus- } \\
\text { tomer satisfaction } \\
\rightarrow \text { WOM intention } \\
\text { d }\end{array}$ & - & - & - & 0.01 & {$[-0.12$} & & $7 \mathrm{a}$ \\
\hline $\begin{array}{l}\text { Index of moderated } \\
\text { mediation (Entertain- } \\
\text { ment value) }\end{array}$ & - & - & - & 0.08 & {$[-0.05$} & & $7 b$ \\
\hline $\begin{array}{l}\text { Discount } \\
\text { evaluation } \rightarrow \text { Cus- } \\
\text { tomer satisfaction } \\
\rightarrow \text { WOM intention }\end{array}$ & - & - & - & 0.08 & {$[-0.04$} & & $8 a$ \\
\hline $\begin{array}{l}\text { Index of moderated } \\
\text { mediation (Discount } \\
\text { evaluation) }\end{array}$ & - & - & - & 0.08 & {$[-0.05$} & & $8 b$ \\
\hline
\end{tabular}

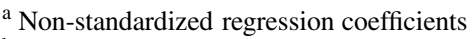

b Mean centered

${ }^{c}$ Bootstrap confidence intervals (for a type I error of $0.05 ; 10000$ bootstrap samples)

${ }^{\mathrm{d}}$ Conditional on mean discount evaluation

${ }^{\mathrm{e}}$ Conditional on mean entertainment value

\section{Discussion and Conclusion}

Customer Satisfaction Study I identified a positive effect of gambled promotions on customer satisfaction. Furthermore, the entertainment value of the promotion partially mediated this effect; a promising entertainment value boosted customer satisfaction. Only for very high levels of discount evaluation did entertainment value not matter. The analyses accounted for other assessments of the promotion, which did not significantly explain differences in satisfaction and WOM intention. Remarkably, the gambled price promotion affected customer satisfaction favorably, despite high evaluations of the candy shop throughout all four experimental conditions. The respondents seemed to discover substantial benefits from both gambled discounts, which transferred into higher satisfaction ratings. 
Study II did not reveal a positive effect of gambled price promotion on customer satisfaction. Nevertheless, the experimental and control groups appeared to differ in this respect. The different distributions of customer satisfaction indicated that both customers who were more dissatisfied and those who were more satisfied existed in the EG while satisfaction was bell-shaped for the CG. Consequently, as a result of the promotional event, more people appraised the store either very favorably or very badly. This could not be linked to entertainment benefits. However, discount evaluation had an influence on customer satisfaction. Consumers who evaluated the discount more positively were also more satisfied with the seller. However, with higher stakes, entertainment value becomes less important for customer satisfaction. This, in turn, might imply a need to manage consumers' assessments of the outcome of the gamble by the seller.

WOM Intention Both studies detected a positive effect of gambled price promotions on WOM intention. Furthermore, Study I supported the claim that this effect is fully mediated by the entertainment value of the promotion. In line with this evidence, Study II discovered that WOM intention correlated positively with the entertainment value of the promotion. Customers were more willing to recommend the store when they participated in a game, especially when they considered the game enjoyable. These results underscore the positive effects of gambled price promotions in terms of favorable communication by WOM.

General Marketing Implications The results of the two studies vary in detail; however, they are consistent in three main findings: (1) Shoppers endorsed gambled price promotions. Overall, customer satisfaction and WOM intention were higher when conducting a gambled price promotion. Furthermore, people spent more money in the presence of a risk-involving campaign in both studies. (2) Entertainment benefits were found to be drivers of the success of a gambled price promotion. (3) Customers who believe that they won the game (i.e., they positively evaluated the discount) are more satisfied. However, this assessment is far from objective. The consumers experienced difficulties in the assessment of probabilities and the outcomes of the game. Instead, in the low-stakes contests, the consumers did not seem to care much about the result but rather enjoyed gambling for its own sake. In the high-stakes promotion, the objective outcome did not influence WOM intention. However, subjective evaluations were linked to customer satisfaction.

As products of quasi-experimental field studies, the studies show high external validity and are based upon realistic samples. The candy shop of Study I primarily targeted wealthier and older customers. The management of the furniture chain of Study II successfully addressed mass markets rather than niches, which permits the results to be generalized to more diverse populations, at least in the country of investigation.

Managerial Implications Like operating a casino and relying on probability laws, risk-involving price promotions poses no real monetary risk to retailers if they conduct a sufficient number of replications of the gamble. The odds must be designed in accordance with the margins for the business or the allowances granted by the 
manufacturers. Taken together, this new element of the promotional mix appears to be a relatively inexpensive but efficient marketing instrument.

Retailers are encouraged to focus on the entertainment quality of the campaign, especially when running a low-stakes gamble. Our research suggests that increasing the entertainment or experiential quality of shopping by extending the fun nature of the promotional campaign (e.g., throwing the dice in a public setting) is beneficial for the seller (e.g., Pine and Gilmore 1999). Anecdotal evidence from personal interviews with retail managers and consumers supports this view. The CEO of the furniture retail chain endorsed such views by indicating that he believed that customers enjoyed the games for the sake of playing a game rather than for the potential discount. Such a characteristic engenders positive responses in customers during and after the promotion, even when they are not among the lucky winners. Content issues, such as perceived time pressure (i.e., the time available for the respective shopping task), might be of importance.

In high-stakes contexts, the seller should seek to alleviate the grief of some customers who feel that they have lost in the game. A remedy to this problem might be to have more consumers "winning" in the game. On the one hand, this could be achieved by paying higher discounts. However, this is costly. On the other hand, we observed that customers' assessments of the discount could be considered to not be very rational. Perceiving an outcome as "satisfactory" or "unsatisfactory" appeared to be subjective. Therefore, sellers should engage in the framing of the outcome of the promotion and try to influence the subjective assessments of discounts selling all outcomes as "wins". Furthermore, recent findings have identified boundaries for risk and uncertainty involving price promotions. When consumers focus on the details of a gamble or promotion rather than the big picture of the promotion, they have a stronger preference for risky and uncertain gambles (Duke et al. 2018). Therefore, more entertaining promotions that focus on the aspects of the game rather than the discount might be more promising.

Limitations and Future Research This paper reports the results of two field studies. Study II replicated and extended Study I by using a distinct retail category, a high-stakes situation, a different framing of the campaign, and a divergent format (in particular, the $100 \%$ discount option in Study I). Furthermore, the customers in Study II might have been more familiar with the type of promotion than the customers in Study I.

The field study design limited the refinement of internal validity, and the complete control of many other potential drivers of customer approval of the store could not be established. The nature of field studies also accounts for the lack of a random assignment of subjects to different experimental conditions and for the moderate sample sizes. This limitation offers avenues for future research to utilize laboratory settings for better control of conditions. Furthermore, the constraints of the cooperation partners limited our research design to a brief questionnaire and, therefore, to single-item measures.

This paper investigated two specific frames of gambled price promotions (i.e., a "wheel of fortune" and a dice game). Clearly, many alternative settings are possible. Managers might increase the gambling aspect of the promotion. As an example, 
scratch cards or a slot machine could be perceived as even more amusing than spinning a wheel or throwing dice. When matching symbols determine the discount, shoppers might experience a loss as a near-win (e.g., two matches but one mismatch) (Gilovich and Douglas 1986). Furthermore, other types of promotions with unknown discounts could be investigated. Some retailers run promotions where the discount is determined by external events (Ailawadi et al. 2014) or given without active consumer participation (e.g., every 10th customer receives a discount by 100\%). Future research could investigate such types of framing effects and manipulate the entertainment value of the promotion experimentally.

This paper examined gambled promotions that are genuinely risky in giving each participant the same objective expected discount. As an alternative, the seller could add a skill-based component in the promotion. This could be achieved by incorporating a low-to-moderate difficulty ball game (e.g., scoring a goal, hitting a target) or card game (e.g., blackjack). Consumers who are provided with an unknown reward for performing a specific action are more likely to engage in repeat purchases (Shen et al. 2019). Further studies regarding the role of the degree of consumer participation on customer satisfaction and WOM intention would be worthwhile.

Previous studies have found that price promotions hurt brand loyalty (Gedenk and Neslin 2000). As customer satisfaction is an important antecedent of loyalty (Oliver 1999), increasing customer satisfaction through gambled price promotions might help to mitigate the negative effect of price promotions on store loyalty. Further research should be carried out to establish these potential downstream implications.

There are also contributions that point to boundary conditions of promotions with unknown consequences. Consumers might reject these offers because they are reactant (Bertini and Aydinli 2020), because they want to maintain their freedom of choice (Briley et al. 2018) or because they engage in cognitive decision making (Laran and Tsiros 2013). Further research might investigate how these aspects influence customer satisfaction and WOM in this context.

Finally, investigating the long-term effects of such gambled promotions is likely to yield thought-provoking inquiries in this area.

Conflict of interest K. Akbari and U. Wagner declare that they have no competing interests.

Open Access This article is licensed under a Creative Commons Attribution 4.0 International License, which permits use, sharing, adaptation, distribution and reproduction in any medium or format, as long as you give appropriate credit to the original author(s) and the source, provide a link to the Creative Commons licence, and indicate if changes were made. The images or other third party material in this article are included in the article's Creative Commons licence, unless indicated otherwise in a credit line to the material. If material is not included in the article's Creative Commons licence and your intended use is not permitted by statutory regulation or exceeds the permitted use, you will need to obtain permission directly from the copyright holder. To view a copy of this licence, visit http://creativecommons.org/licenses/by/4. $0 \%$. 


\section{Appendix}

Table 5 Measurement and operationalization

\begin{tabular}{ll}
\hline Construct & Operationalization \\
\hline $\begin{array}{l}\text { Discount evaluation } \\
\text { Expected discount }\end{array}$ & I am satisfied with the obtained discount. ${ }^{\mathrm{a}}$ \\
Realized discount & What discount do you expect from the promotion ${ }^{\mathrm{b}}$ \\
Purchase value & Observed by a research assistant ${ }^{\mathrm{b}}$ \\
Entertainment value & Invoice amount observed by a research assistant ${ }^{\mathrm{c}}$ \\
Customer satisfaction & I consider the [wheel of fortune/dice] promotion to be entertaining. ${ }^{\mathrm{a}}$ \\
WOM intention & I am satisfied with [name of the seller]. ${ }^{\text {a }}$ \\
Age & I will recommend [name of the seller] to others. ${ }^{\mathrm{d}}$ \\
Gender & Please indicate your age \\
\hline
\end{tabular}

a 5-point rating scale: 1 -do not agree, 5-completely agree

${ }^{\mathrm{b}}$ Response in $\%$

c In $€$

d 5-point rating scale: 1 -do not agree, 5-completely agree (Study I); 3-point rating scale: 1 -no intention to engage in WOM, 3 -intention to engage in WOM (Study II)

Table 6 MANOVA of experimental condition on entertainment value, discount evaluation, customer satisfaction, WOM intention (Study I)

\begin{tabular}{|c|c|c|c|c|c|c|c|c|}
\hline \multirow{4}{*}{$\begin{array}{l}\text { System- } \\
\text { level } \\
\text { Dependent } \\
\text { variable } \\
\text { Omnibus } \\
\text { test }\end{array}$} & \multicolumn{8}{|c|}{ Pillai's trace $=0.28, F_{8}, 296=6.13 p<0.01$} \\
\hline & \multicolumn{2}{|c|}{$\begin{array}{l}\text { Entertainment } \\
\text { value }\end{array}$} & \multicolumn{2}{|c|}{$\begin{array}{l}\text { Discount } \\
\text { evaluation }\end{array}$} & \multicolumn{2}{|c|}{$\begin{array}{l}\text { Customer } \\
\text { satisfaction }\end{array}$} & \multicolumn{2}{|c|}{ WOM intention } \\
\hline & $F_{2,150}$ & $p$-level & $F_{2,150}$ & $p$-level & $F_{2,150}$ & $p$-level & $F_{2,150}$ & $p$-level \\
\hline & 5.03 & $<0.01$ & 12.60 & $<0.01$ & 8.04 & $<0.01$ & 4.37 & 0.01 \\
\hline & \multicolumn{8}{|c|}{$p$-level for Tukey HSD pairwise comparisons } \\
\hline & EG1 & EG2 & EG1 & EG2 & EG1 & EG2 & EG1 & EG2 \\
\hline EG2 & 0.63 & - & $<0.01$ & - & 0.09 & - & 0.43 & - \\
\hline CG2 & $<0.01$ & 0.04 & 0.90 & $<0.01$ & $<0.01$ & 0.05 & $<0.01$ & 0.11 \\
\hline
\end{tabular}

EG1: gambled discount (average: 5\%, range: 1-10\%), EG2: gambled discount (average: 5\%, range: 1-100\%), CG2: regular discount $5 \%$ 


\section{References}

Ailawadi, K.L., K. Gedenk, T. Langer, Y. Ma, and S.A. Neslin. 2014. Consumer response to uncertain promotions: an empirical analysis of conditional rebates. International Journal of Research in Marketing 31(1):94-106.

Alavi, S., T. Bornemann, and J. Wieseke. 2015. Gambled price discounts: a remedy to the negative side effects of regular price discounts. Journal of Marketing 79(2):62-78.

Alba, J.W., and J.W. Hutchinson. 1987. Dimensions of consumer expertise. Journal of Consumer Research 13(4):411-454.

Anderson, E.W. 1998. Customer satisfaction and word of mouth. Journal of Service Research 1(1):5-17.

Arndt, J. 1967. Role of product-related conversations in the diffusion of a new product. Journal of Marketing Research 4(3):291.

Astor, P.J., M.T.P. Adam, C. Jähnig, and S. Seifert. 2013. The joy of winning and the frustration of losing: a psychophysiological analysis of emotions in first-price sealed-bid auctions. Journal of Neuroscience, Psychology, and Economics 6(1):14-30.

Bar-Hillel, M., and D. Budescu. 1995. The elusive wishful thinking effect. Thinking \& Reasoning 1(1):71-103.

Bar-Hillel, M., D.V. Budescu, and M. Amar. 2008. Predicting world cup results: Do goals seem more likely when they pay off? Psychonomic Bulletin \& Review 15(2):278-283.

Barsky, J., and L. Nash. 2003. Customer satisfaction: applying concepts to industry-wide measures. Cornell Hotel and Restaurant Administration Quarterly 44(5/6):173-183.

Bauer, D.J., and P.J. Curran. 2005. Probing interactions in fixed and multilevel regression: inferential and graphical techniques. Multivariate Behavioral Research 40(3):373-400.

Benhsain, K., and R. Ladouceur. 2004. Knowledge in statistics and erroneous perceptions in gambling. Gambling Research: Journal of the National Association for Gambling Studies (Australia) 16(1):25-31.

Berger, J. 2014. Word of mouth and interpersonal communication: a review and directions for future research. Journal of Consumer Psychology 24(4):586-607.

Berger, J., and R. Iyengar. 2013. Communication channels and word of mouth: how the medium shapes the message. Journal of Consumer Research 40(3):567-579.

Berger, J., and E.M. Schwartz. 2011. What drives immediate and ongoing word of mouth? Journal of Marketing Research 48(5):869-880.

Berlyne, D.E. 1970. Novelty, complexity, and hedonic value. Perception \& Psychophysics 8(5):279-286.

Bertini, M., and A. Aydinli. 2020. Consumer reactance to promotional favors. Journal of Retailing 96(4):578-589.

Briley, D.A., S. Danziger, and E. Li. 2018. Promotional games: trick or treat? Journal of Consumer Psychology 28(1):99-114.

Chandon, P., B. Wansink, and G. Laurent. 2000. A benefit congruency framework of sales promotion effectiveness. Journal of Marketing 64(4):65-81.

Chung, M., E. Ko, H. Joung, and S.J. Kim. 2020. Chatbot e-service and customer satisfaction regarding luxury brands. Journal of Business Research 117:587-595.

Churchill, G.A., Jr., and C. Surprenant. 1982. An investigation into the determinants of customer satisfaction. Journal of Marketing Research 19(4):491-504.

Dhar, S., C. González-Vallejo, and D. Soman. 1995. Brand promotions as a lottery. Marketing Letters 6(3):221-233.

Dichter, E. 1966. How word-of-mouth advertising works. Harvard Business Review 6(44):147-166.

Ding, M., J. Eliashberg, J. Huber, and R. Saini. 2005. Emotional bidders-An analytical and experimental examination of consumers' behavior in a Priceline-like reverse auction. Management Science 51(3):352-364.

Duke, K.E., K. Goldsmith, and O. Amir. 2018. Is the preference for certainty always so certain? Journal of the Association for Consumer Research 3(1):63-80.

Fang, X., and J.C. Mowen. 2009. Examining the trait and functional motive antecedents of four gambling activities: slot machines, skilled card games, sports betting, and promotional games. Journal of Consumer Marketing 26(2):121-131.

Forgas, J.P. 1999. Soziale Interaktion und Kommunikation: Eine Einführung in die Sozialpsychologie, 4th edn., Weinheim: Beltz.

Francis, K.L., N.A. Dowling, A.C. Jackson, D.R. Christensen, and H. Wardle. 2015. Gambling motives: application of the reasons for gambling questionnaire in an Australian population survey. Journal of Gambling Studies 31(3):807-823. 
Gaertig, C., and J.P. Simmons. 2020. Why (and when) are uncertain price promotions more effective than equivalent sure discounts? Working Paper.

Gedenk, K., and S.A. Neslin. 2000. Die Wirkung von Preis- und Nicht-Preis-Promotions auf die Markenloyalität. Schmalenbachs Zeitschrift für betriebswirtschaftliche Forschung 52(4):370-392.

Gedenk, K., S. Rudek, and M.H. Teichmann. 2001. Gewinnspiele im Internet. Marketing ZFP 23(2):117128.

Gee, P., K.R. Coventry, and D. Birkenhead. 2005. Mood state and gambling: using mobile telephones to track emotions. British Journal of Psychology (London, England 1953) 96(Pt 1):53-66.

Gilovich, T. 1983. Biased evaluation and persistence in gambling. Journal of Personality and Social Psychology 44(6):1110-1126.

Gilovich, T., and C. Douglas. 1986. Biased evaluations of randomly determined gambling outcomes. Journal of Experimental Social Psychology 22(3):228-241.

Goldsmith, K., and O. Amir. 2010. Can uncertainty improve promotions? Journal of Marketing Research 47(6):1070-1077.

Hayes, A.F. 2018. Introduction to mediation, moderation, and conditional process analysis: a regressionbased approach. New York: Guilford.

Heath, C., C. Bell, and E. Sternberg. 2001. Emotional selection in memes: the case of urban legends. Journal of Personality and Social Psychology 81(6):1028-1041.

Hock, S.J., R. Bagchi, and T.M. Anderson. 2020. Promotional games increase consumer conversion rates and spending. Journal of Consumer Research 47(1):79-99.

Holbrook, M.B., R.W. Chestnut, T.A. Oliva, and E.A. Greenleaf. 1984. Play as a consumption experience: the roles of emotions, performance, and personality in the enjoyment of games. Journal of Consumer Research 11(2):728-739.

Holmes, J.H., and J.D. Lett. 1977. Product sampling and word of mouth. Journal of Advertising Research 17(5):35-40.

Kahneman, D., and A. Tversky. 1979. Prospect theory: an analysis of decision under risk. Econometrica 47(2):263-291.

Kamleitner, B., D.R. Mandel, and M.K. Dhami. 2011. Risky discounts: Do people prefer them on a peritem or per-purchase basis and why? Journal of Economic Psychology 32(6):951-961.

Kendi-Prill, K. 2017. DAS sollten sich Prinz William und Herzogin Kate anschauen! https://www. heidelberg24.de/heidelberg/heidelberg-unsere-leser-haben-abgestimmt-sollen-sich-prinz-williamherzogin-kate-anschauen-8412582.html. Accessed 27 Oct 2020. Heidelberg 24. June 19th, 2017.

Krishna, A. 2016. A clearer spotlight on spotlight: understanding, conducting and reporting. Journal of Consumer Psychology 26(3):315-324.

Krüger, F. 2016. The influence of culture and personality on customer satisfaction. Wiesbaden: Springer.

Laran, J., and M. Tsiros. 2013. An investigation of the effectiveness of uncertainty in marketing promotions involving free gifts. Journal of Marketing 77(2):112-123.

Lee, C.-Y., C.K. Morewedge, G. Hochman, and D. Ariely. 2019. Small probabilistic discounts stimulate spending: pain of paying in price promotions. Journal of the Association for Consumer Research 4(2):160-171.

Levy, S.J. 1959. Symbols for sale. Harvard Business Review 37(4):117-124.

Lovett, M.J., R. Peres, and R. Shachar. 2013. On brands and word of mouth. Journal of Marketing Research 50(4):427-444.

Lynch, J.G., E.T. Bradlow, J.C. Huber, and D.R. Lehmann. 2015. Reflections on the replication corner: in praise of conceptual replications. International Journal of Research in Marketing 32(4):333-342.

Malhotra, D. 2010. The desire to win: the effects of competitive arousal on motivation and behavior. $O r$ ganizational Behavior and Human Decision Processes 111(2):139-146.

Martín-Consuegra, D., A. Molina, and Á. Esteban. 2007. An integrated model of price, satisfaction and loyalty: an empirical analysis in the service sector. Journal of Product \& Brand Management 16(7):459-468.

Mazar, N., K. Shampanier, and D. Ariely. 2017. When retailing and Las Vegas meet: probabilistic free price promotions. Management Science 63(1):250-266.

Oliver, R.L. 1980. A cognitive model of the antecedents and consequences of satisfaction decisions. Journal of Marketing Research 17(4):460-469.

Oliver, R.L. 1999. Whence consumer loyalty? Journal of Marketing 63(4_suppl1):33-44.

Pantano, E., and G. Naccarato. 2010. Entertainment in retailing: the influences of advanced technologies. Journal of Retailing and Consumer Services 17(3):200-204.

Peters, K., and Y. Kashima. 2007. From social talk to social action: shaping the social triad with emotion sharing. Journal of Personality and Social Psychology 93(5):780-797. 
Pine, B.J., and J.H. Gilmore. 1998. Welcome to the experience economy. Harvard Business Review 76(4):97-105.

Pine, B.J., and J.H. Gilmore. 1999. The experience economy: work is theatre \& every business a stage. Boston, MA: Harvard Business Press.

Richins, M.L. 1983. Negative word-of-mouth by dissatisfied consumers: a pilot study. Journal of Marketing 47(1):68.

Roberts, K.W.S. 2004. Lovemarks: the future beyond brands, 1st edn., New York: Power House Books.

Santini, F.O., W. Ladeira Jr., and C.H. Sampaio. 2018. The role of satisfaction in fashion marketing: a metaanalysis. Journal of Global Fashion Marketing 9(4):305-321.

Schlesinger, L.A., and J.L. Heskett. 1991. The service-driven service company. Harvard Business Review 69(5):71-81.

Schmitt, B.H. 1999. Experiential marketing: how to get customers to sense, feel, think, act, and relate to your company and brands. New York: Free Press.

Sernovitz, A. 2006. Word of mouth marketing. How smart companies get people talking. Dearborn: Kaplan Business.

Shen, L., A. Fishbach, and C.K. Hsee. 2015. The motivating-uncertainty effect: uncertainty increases resource investment in the process of reward pursuit. Journal of Consumer Research 41(5):1301-1315.

Shen, L., C.K. Hsee, and J.H. Talloen. 2019. The fun and function of uncertainty: uncertain incentives reinforce repetition decisions. Journal of Consumer Research 46(1):69-81.

Sheth, J.N., B.I. Newman, and B.L. Gross. 1991. Why we buy what we buy: a theory of consumption values. Journal of Business Research 22(2):159-170.

Smith, G., M. Levere, and R. Kurtzman. 2009. Poker player behavior after big wins and big losses. Management Science 55(9):1547-1555.

Söderlund, M., and C.-R. Julander. 2009. Physical attractiveness of the service worker in the moment of truth and its effects on customer satisfaction. Journal of Retailing and Consumer Services 16(3):216-226.

Swan, J.E., and R.L. Oliver. 1989. Postpurchase communications by consumers. Empirical Generalizations in Retailing 65(4):516.

Teichmann, M.H., K. Gedenk, and M. Knaf. 2005. Consumers' preferences for online and offline sweepstakes and contests. Marketing ZFP 27(JRM 2):76-90.

de Vries, E.L.E., and S. Zhang. 2020. The effectiveness of random discounts for migrating customers to the mobile channel. Journal of Business Research 110:272-281.

Wagner, U., and J. Jamsawang. 2012. Several aspects of psychological pricing: empirical evidence from some Austrian retailers. European Retail Research 25(2):1-19.

Walker, M.B. 1992. The psychology of gambling. New York: Pergamon Press.

Ward, J.C., and R.P. Hill. 1991. Designing effective promotional games: opportunities and problems. Journal of Advertising 20(3):69-81.

Westbrook, R.A. 1987. Product/Consumption-based affective responses and postpurchase processes. Journal of Marketing Research 24(3):258-270.

Yuan, Y.-H.E., and C.K. Wu. 2008. Relationships among experiential marketing, experiential value, and customer satisfaction. Journal of Hospitality \& Tourism Research 32(3):387-410.

Zeithaml, V.A., and M.J. Bitner. 2000. Services marketing: Integrating customer focus across the firm, 2nd edn., Boston: Irwin/McGraw-Hill. 